\title{
Comparative feeding ecology of four sympatric skate species off central California, USA
}

\author{
J. J. Bizzarro • H. J. Robinson • C. S. Rinewalt • \\ D. A. Ebert
}

Published online: 25 October 2008

(C) Springer Science + Business Media B.V. 2008

Erratum to: Environ Biol Fish (2007) 80:197-220

DOI 10.1007/s10641-007-9241-6

Erroneous standard error values of the percentage index of relative importance (\%IRI) were presented in the above article (see Figure 3); leading to the unsubstantiated conclusion that \%IRI calculations were much less precise than those of the percentage geometric index of importance (\%GII). When corrected, standard error estimates of \%IRI were actually only slightly less precise than those of \%GII. For example, \%IRI and \%GII values (mean $\pm \mathrm{SE}$ ) corresponding to the most important prey taxa of the sandpaper skate (Bathyraja kincaidii) were: shrimplike crustaceans $(\% \mathrm{IRI}=65.7 \pm 4.1 ; \% \mathrm{GII}=50.2 \pm 2.5)$; polychaetes $(\% \mathrm{IRI}=13.4 \pm 2.2 ; \% \mathrm{GII}=16.9 \pm 2.2)$; and cephalopods $(\% \mathrm{IRI}=9.9 \pm 1.9 ; \% \mathrm{GII}=13.8 \pm 1.8)$. Although precision of $\%$ GII calculations was always greater than that of \%IRI for our data set, measures of occurrence differ between indices and this result may not be typical.

The online version of the original article can be found at http:// dx.doi.org/10.1007/s10641-007-9241-6.

J. J. Bizzarro $(\bowtie) \cdot$ H. J. Robinson $\cdot$ C. S. Rinewalt $\cdot$

D. A. Ebert

Pacific Shark Research Center,

Moss Landing Marine Laboratories,

8272 Moss Landing Rd.,

Moss Landing, CA 95039, USA

e-mail: jbizzarro@mlml.calstate.edu 